\title{
HYDROGEN ABSORPTION/DESORPTION IN A METAL HYDRIDE REACTOR ACCOUNTING FOR VARIED EFFECTIVE THERMAL CONDUCTIVITY
}

\author{
Chih-Yuan Wang \\ Department of Mechanical and Mechatronic Engineering, National Taiwan Ocean University, Keelung, Taiwan, R.O.C. \\ Hwa-Chong Tien \\ Department of Mechanical and Mechatronic Engineering, National Taiwan Ocean University, Keelung, Taiwan, R.O.C., \\ hctien@ntou.edu.tw \\ San-Der Chyou \\ Taiwan Power Company, Taipei, Taiwan, R.O.C. \\ Nang-Nong Huang \\ Department of Mechanical and Mechatronic Engineering, National Taiwan Ocean University, Keelung, Taiwan, R.O.C. \\ Shing-Hoa Wang \\ Department of Mechanical and Mechatronic Engineering, National Taiwan Ocean University, Keelung, Taiwan, R.O.C.
}

Follow this and additional works at: https://jmstt.ntou.edu.tw/journal

Part of the Mechanical Engineering Commons

\section{Recommended Citation}

Wang, Chih-Yuan; Tien, Hwa-Chong; Chyou, San-Der; Huang, Nang-Nong; and Wang, Shing-Hoa (2011) "HYDROGEN ABSORPTION/DESORPTION IN A METAL HYDRIDE REACTOR ACCOUNTING FOR VARIED EFFECTIVE THERMAL CONDUCTIVITY," Journal of Marine Science and Technology. Vol. 19: Iss. 2, Article 9.

DOI: $10.51400 / 2709-6998.2152$

Available at: https://jmstt.ntou.edu.tw/journal/vol19/iss2/9

This Research Article is brought to you for free and open access by Journal of Marine Science and Technology. It has been accepted for inclusion in Journal of Marine Science and Technology by an authorized editor of Journal of Marine Science and Technology. 
HYDROGEN ABSORPTION/DESORPTION IN A METAL HYDRIDE REACTOR ACCOUNTING FOR VARIED EFFECTIVE THERMAL CONDUCTIVITY

Acknowledgements

This work was carried out with financial support from the Taiwan Power Company of the ROC, Taiwan, under contract TPC-546-2415-9402C (from July 2004 to December 2005). 


\title{
HYDROGEN ABSORPTION/DESORPTION IN A METAL HYDRIDE REACTOR ACCOUNTING FOR VARIED EFFECTIVE THERMAL CONDUCTIVITY
}

\author{
Chih-Yuan Wang*, Hwa-Chong Tien*, San-Der Chyou**, Nang-Nong Huang*, \\ and Shing-Hoa Wang*
}

Key words: metal hydride, hydrogen absorption/desorption, effective thermal conductivity.

\begin{abstract}
This paper investigates the effect of varied effective thermal conductivity on the hydrogen absorption/desorption in a metal hydride (MH) reactor. The effective thermal conductivity of a metal hydride bed was measured by performing steady-state experiment and then compared with the results obtained by employing an existing model. Good agreement was found. Next, numerical simulation on the performance of hydrogen absorption/desorption of the $\mathrm{MH}$ reactor was conducted by assuming either varied or constant effective thermal conductivity. Corresponding hydrogen absorption/desorption experiment was performed for comparison. It was found that numerical simulation accounting for varied effective thermal conductivity agrees with the experimental data much better than that with fixed thermal conductivity. This work clearly indicates the need of utilizing the varied effective thermal conductivity model in the design of $\mathrm{MH}$ reactors.
\end{abstract}

\section{INTRODUCTION}

Hydrogen storage constitutes an important field for the development of utilizing hydrogen energy. Metal hydrides (MH) possess several superiorities to other hydrogen storage media/ means in several aspects such as safety and compact storage. A lot of heat is released during hydrogen absorption process, whereas much heat is absorbed during hydrogen desorption process. Thermal conductivity of a metal hydride bed has a direct impact on the performance of the hydrogen reactors. To

Paper submitted 12/17/09; revised 03/08/10; accepted 03/11/10. Author for correspondence: Hwa-Chong Tien (e-mail:hctien@ntou.edu.tw).

*Department of Mechanical and Mechatronic Engineering, National Taiwan Ocean University, Keelung, Taiwan, R.O.C.

**Taiwan Power Company, Taipei, Taiwan, R.O.C. accurately predict and properly design the performance of a hydrogen-storage reactor, the determination of the thermal conductivity of the reaction bed is crucial.

Many experimental and theoretical works have been conducted for studying the effective thermal conductivity $\left(K_{\mathrm{e}}\right)$ of metal hydride beds. Suda and co-workers $[15,16]$ experimentally investigated the thermal conductivity of $\mathrm{TiMn}_{1.5}$ bed under steady-state conditions. Based on the experimental data, an empirical equation was proposed to describe $K_{\mathrm{e}}$ for the $\mathrm{TiMn}_{1.5}$ bed as a function of pressure and composition. Suissa et al. [18] studied $K_{\mathrm{e}}$ of $\mathrm{Mg}_{2} \mathrm{NiH}_{4}$ and $\mathrm{MmNi}_{4} \mathrm{FeH}_{5.2}$ hydride beds experimentally. They concluded that in engineering applications the $K_{\mathrm{e}}$ of powdered metal hydrides can be assumed in the range of 1 to $2 \mathrm{Wm}^{-1} \mathrm{~K}^{-1}$. Ishido et al. [9] employed a non-stationary hot-wire method to measure $K_{\mathrm{e}}$ of $\mathrm{Mg}, \mathrm{Mg} / 10$ wt.\% $\mathrm{Ni}$, and $\mathrm{Mg}_{2} \mathrm{Ni}$ hydride powder beds under high temperature and hydrogen pressure conditions. Moreover, to enhance the thermal conductivity of the MH beds, Suda et al. [17] developed hydride composites which were composed of the hydride powder and a metal structure $(\mathrm{Cu}, \mathrm{Ni}$ or $\mathrm{Al})$. Empirical equations were derived for estimating $K_{\mathrm{e}}$ according to the experimental results.

Basically, each empirical equation for $K_{\mathrm{e}}$ is applicable to a specific metal hydride bed. Sun and Deng [19] developed a theoretical model for estimating $K_{\mathrm{e}}$ in various $\mathrm{MH}$ beds. The dependence of $K_{\mathrm{e}}$ on several parameters was studied, which included hydrogen pressure and concentration, reaction temperature, void fraction, and diameter and conductivity of the MH particle. In [20], Sung and Deng measured $K_{\mathrm{e}}$ of the $\mathrm{MINi}_{4.5} \mathrm{Mn}_{0.5}$ bed and compared it with the theoretical results. Good agreement was found.

Aside from the effective thermal conductivity, a lot of numerical studies have been conducted to investigate the performance of the hydrogen storage devices. These works can be mainly classified into two categories with the assumption that the solid phase (metal hydride powder) is at either local thermal equilibrium $[1,2,4-7,12-14,21-23]$ or non-local thermal equilibrium $[10,11,25]$ with the gas phase (hydrogen). 
It is noted that in the above-mentioned studies [1, 2, 4-7, 10-14, $21-23,25]$, the effective thermal conductivity was assumed to be a constant.

Among various hydrogen-storage materials, $\mathrm{La}_{5} \mathrm{Ni}$ and associated $\mathrm{AB}_{5}$ compounds can absorb and desorb hydrogen at room temperature and hence they are considered as good hydrogen absorbers. In addition, the absorption/desorption performance of $\mathrm{La}_{5} \mathrm{Ni}$ is quite stable. Therefore, $\mathrm{La}_{5} \mathrm{Ni}$ and associated $\mathrm{AB}_{5}$ compounds are often used in hydrogen-storage reactors. It is essential to accurately predict the performance of the hydrogen-storage reactors for a better design. The present work is composed of three parts. First, Sung and Deng's model [19] is used to predict $K_{\mathrm{e}}$ of a $\mathrm{La}_{5} \mathrm{Ni}$ bed under various pressures and temperatures. Next, experiments are conducted for measuring $K_{\mathrm{e}}$ of the $\mathrm{La}_{5} \mathrm{Ni}$ bed. Finally, hydrogen charging/discharging experiments and associated numerical simulations using the varied $K_{\mathrm{e}}$ model are performed for a hydrogen-storage reactor filled with $\mathrm{La}_{5} \mathrm{Ni}$. Both numerical and experimental results are compared and discussed. This study will clearly indicate the need of using varied $K_{\mathrm{e}}$ model for designing hydrogen-storage reactors.

\section{EFFECTIVE THERMAL CONDUCTIVITY MODEL AND EXPERIMENT}

\section{Effective Thermal Conductivity Model}

The Sun and Deng's model of $K_{\mathrm{e}}$ in $\mathrm{MH}$ beds is similar to that in the general packed beds. Three mechanisms were considered in [19]. Based on this model, the effective thermal conductivity assumes the following form:

$$
\begin{aligned}
K_{e}= & {\left[1-\frac{4}{\pi}(1-\varepsilon)\right]\left(K_{g}^{*}+r_{p} h_{r v}\right) } \\
& +\frac{(4 / \pi)(1-\varepsilon)(1-\tan \theta)}{\frac{\pi / 4-\tan \theta}{(1-\tan \theta) K_{s}^{*}}+\frac{1-\pi / 4}{(1-\tan \theta) K_{g}^{*}+(1-\pi / 4) r_{p} h_{r s}}} \\
& +\frac{4}{\pi}(1-\varepsilon)(\tan \theta) K_{s}^{*}
\end{aligned}
$$

where $\varepsilon, r_{p}$, and $\theta$ denote the void fraction, the radius of the particles, and the contact angle between solid particles, and $h_{r s}$ and $h_{r v}$ the heat transfer coefficients of thermal radiation from solid surface to solid surface and from void to void, respectively. The expressions of $h_{r s}$ and $h_{r v}$ are written as

$$
h_{r s}=\frac{0.2269 \omega}{2-\omega}\left(\frac{T}{100}\right)^{3}
$$

and

$$
h_{r v}=\frac{0.2269}{1+\frac{\varepsilon}{2(1-\varepsilon)} \times \frac{1-\omega}{\omega}}\left(\frac{T}{100}\right)^{3}
$$

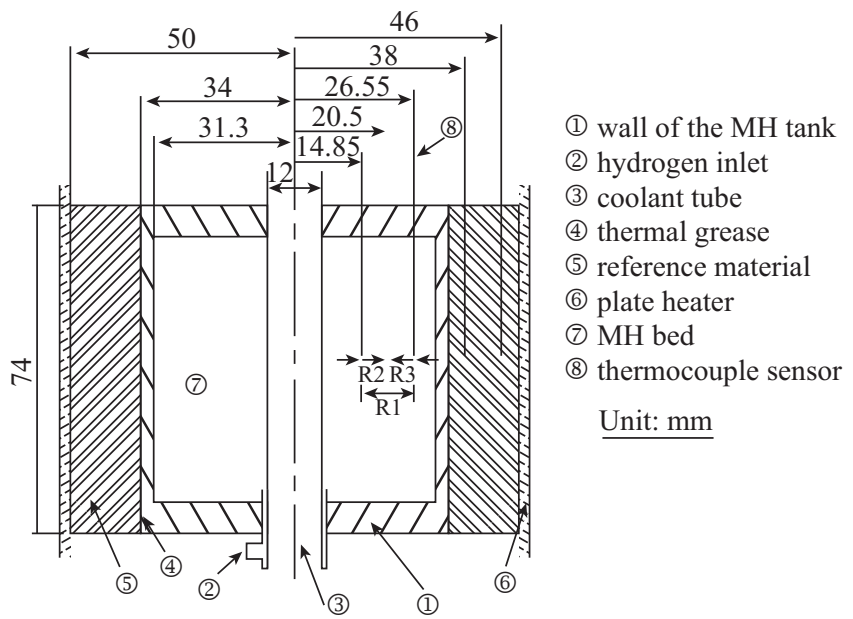

Fig. 1. The experimental set-up for measuring the effective thermal conductivity of metal hydride.

In Eqs. (2a) and (2b), $T$ and $\omega$, separately, denote the temperature and the emissivity of solid surfaces. The thermal conductivities of hydrogen and metal hydride particles in Eq. (1), $K_{g}^{*}$ and $K_{s}^{*}$, account for the effects of hydrogen pressure and hydrogen concentration, respectively. They are related to $K_{g}$ and $K_{s}$, as described in [19]. In addition, two accommodation coefficients $\beta$ and $\gamma$ are involved in the models [19].

\section{Effective Thermal Conductivity Experiment}

The experimental set-up for measuring the effective thermal conductivity of metal hydride is shown in Fig. 1, which is similar to that described in Suissa et al. [18]. The reaction tank is made of stainless steel and a layer of reference material (nylon MC-803) with thermal conductivity of $0.2 \mathrm{~W} / \mathrm{m}-\mathrm{K}$ is attached to the outer wall of the tank. This tank contains 600 grams of $\mathrm{LaNi}_{5}$ powder. To ensure good thermal contact, thermal grease is applied at the interface between the tank wall and the reference material. Electric heater $(700 \mathrm{~W}$ in plate) is attached to the outer surface of the reference material to provide heating power. Finally, insulation material (not shown) is applied to the outer surface of the tank to reduce the heat loss in both axial and radial directions. A cooling tank provides cooling water flowing inside a stainless pipe of outer diameter 12 $\mathrm{mm}$ (SS-316) embedded in the reaction tank to carry the heat away. Four K-type thermocouples are installed in the tank at the same axial position (two in the MH bed and two in the reference material) as shown in Fig. 1.

In this experiment, one dimensional steady heat transfer in radial direction is assumed. The heat flow is calculated based on the temperature readings in the reference material. With heat flow obtained, the effective conductivity of the MH bed can be found as described in $[3,18]$. The conductivity of the reference material is relatively low in order to yield larger temperature gradient and hence more accurate estimation for the heat flow as well as effective conductivity of the MH bed. 


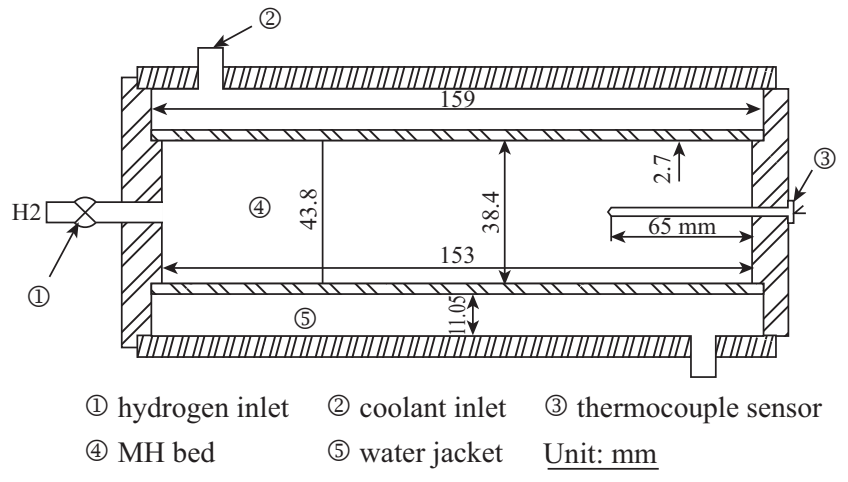

Fig. 2. The schematic diagram of the hydrogen-storage reactor developed in the present work.

The temperatures of the heater and cooling water are set to be $60^{\circ} \mathrm{C}$ and $30^{\circ} \mathrm{C}$ for the experiments of gas pressure effect, and $65^{\circ} \mathrm{C}$ and $15^{\circ} \mathrm{C}$ for that of hydrogen concentration effect. The uncertainty of the experimental values of $K_{\mathrm{e}}$ is estimated to be $\pm 7 \%$.

\section{ABSORPTION/DESORPTION EXPERIMENT AND NUMERICAL SIMULATION}

\section{Absorption/Desorption Experiment}

To conduct the absorption/desorption experiment, a hydrogen-storage reactor is developed. The wall of the reactor is made of stainless steel (AISI 316L). The detailed dimensions are shown in Fig. 2 where the ratio of the length to the radius of the $\mathrm{MH}$ bed is chosen to be 8 . The inner volume of the reactor is $178 \mathrm{~cm}^{3}$ and it is designed to store 700 grams of $\mathrm{LaNi}_{5}$ powder. Cooing or heating water circulates around the outer wall of the MH bed. The whole reactor is wrapped with insulation to reduce heat loss. The hydrogen inlet/exit is located at the center of the left end wall, while a thermocouple is $65 \mathrm{~mm}$ from the center of the right end. This thermocouple is attached to the inner wall of a slender tube (316L) embedded in the $\mathrm{MH}$ bed for measuring the center temperature.

The complete system of the absorption/desorption experiment consists of three subsystems:

(a) Data acquisition system: It records pressure, temperature, hydrogen mass flow and accumulated hydrogen absorbed or desorbed. The uncertainty of the accumulated hydrogen is estimated to be within $\pm 3 \%$.

(b) Heating/cooling system: This system includes a water tank $\left(0 \sim 100^{\circ} \mathrm{C}\right)$, a pump, a water flow meter $(0 \sim 50 \mathrm{~L} / \mathrm{min})$, and associated pipe system.

(c) Gas piping system: a hydrogen vessel, a filter $(0.5 \mu \mathrm{m})$, valves, a gas flow meter, and associated gas pipe system.

\section{Hydrogen Absorption/Desorption Theoretical Model}

Consider a hydrogen storage reactor shown in Fig. 2. The two-dimensional axisymmetric energy equation reads [7, 22]

$$
\frac{\rho_{b} c_{b}}{K_{e}} \frac{\partial T}{\partial t}=\frac{1}{r} \frac{\partial}{\partial r}\left(r \frac{\partial T}{\partial r}\right)+\frac{\partial^{2} T}{\partial z^{2}}-\frac{\rho_{b} \gamma_{h} \Delta H_{f}}{K_{e}}
$$

In Eq. (3), $T, r$, and $t$ denote temperature, radial coordinate, and time, respectively; $\rho_{b}, c_{b}$, and $K_{e}$ are the density, specific heat, and the heat conductivity of $\mathrm{MH}$ bed. In addition, $\gamma_{h}$ is the reaction rate and $\Delta H_{f}$ is the heat of formation which is negative for both hydrogen absorption and desorption. The expression of $\gamma_{h}$ is modeled as

$$
\gamma_{h}=\frac{1000 N}{2 M} \frac{\partial x}{\partial t}
$$

In the above equation $N, M$, and $x$ denote, respectively, the number of metallic atoms, the molecule weight, and the concentration of hydrogen of the $\mathrm{MH}$, which is the ratio of the number of hydrogen atoms to the total number of atoms of the MH. For hydrogen absorption, $\partial x / \partial t$ and $\gamma_{h}$ are positive while negative for hydrogen desorption. One of the popular models for $\partial x / \partial t$ is expressed as follows.

$$
\frac{\partial x}{\partial t}=\eta\left( \pm \frac{P_{b}-P_{e q}}{P_{e q}}\right) \frac{x-x_{F}}{x_{I}-x_{F}} \exp \left(\frac{-E}{R_{u} T}\right)
$$

The parameters in Eq. (5) $\eta, E$, and $R_{u}$ denote the rate constant, activation energy, and universal gas constant, respectively. In addition, $x_{I}$ and $x_{F}$ are the initial and final hydrogen concentrations during the absorption/desorption process; $P_{b}$ and $P_{e q}$ are the pressure in the reactor and equilibrium pressure. Also in Eq. (5) the positive sign is used for absorption, while the negative sign for desorption.

The equilibrium pressure accounting for the effects of hysteresis and plateau slope can be expressed by van't Hoff equation in the following form $[7,8,21]$ :

$$
\ln P_{e q}=\frac{A}{T}+B+f_{p s}+f_{h y s}
$$

In Eq. (6) $A$ and $B$ are constants, and $f_{p s}$ and $f_{\text {hys }}$ denote the coefficients accounting for the effects of plateau slope and hysteresis, respectively. The expressions of $f_{p s}$ and $f_{\text {hys }}$ are written as follows.

$$
\begin{array}{cc}
f_{p s}=\left(x-x_{m}\right) \frac{\partial \ln P_{e q}}{\partial x} & \text { (absorption) } \\
f_{\text {hys }}=\ln \frac{P_{a}}{P_{d}} & \text { (desorption) }
\end{array}
$$

In Eq. (7), $x_{m}$ denotes the intermediate hydrogen concentration, and in Eq. (8a), $P_{a}$ and $P_{d}$ denote the absorption 
Table 1. The properties of $\mathrm{LaNi}_{5}$ used in calculation [3, 8, 24].

\begin{tabular}{|c|c|c|c|c|c|}
\hline$\rho_{\mathrm{MH}}\left(\mathrm{kg} / \mathrm{m}^{3}\right)$ & $\rho_{b}\left(\mathrm{~kg} / \mathrm{m}^{3}\right)$ & $\varepsilon$ & $c_{b}(\mathrm{~kJ} / \mathrm{kg}-\mathrm{K})$ & $K_{e}(\mathrm{~W} / \mathrm{m}-\mathrm{K})$ & $M(\mathrm{~g} / \mathrm{mole})$ \\
\hline 7500 & 4120 & 0451 & 0572 & $\begin{array}{c}1 \text { (fixed) } \\
1 \sim 2 \text { (varied) }\end{array}$ & 432.46 \\
\hline \multicolumn{2}{|c|}{$\Delta H_{f}\left(\mathrm{~kJ} /\right.$ mole of $\left.\mathrm{H}_{2}\right)$} & $A(\mathrm{~K})$ & $B$ & $f_{\text {hys }}$ (absorption) & $f_{\text {hys }}$ (desorption) \\
\hline \multicolumn{2}{|c|}{-28.5} & -3428 & 12.82 & 0.19 & 0 \\
\hline \multicolumn{2}{|c|}{$x_{I}$} & $X_{m}$ & $\left|x_{F}-x_{I}\right|$ & $\frac{\partial \ln P}{\partial x}$ & $\mathrm{wt} \%$ \\
\hline \multicolumn{2}{|c|}{$\begin{array}{c}0 \text { (absorption) } \\
1.02 \text { (desorption) }\end{array}$} & 0.51 & 1.02 & 0.09 & 1.43 \\
\hline \multicolumn{2}{|c|}{$\theta$ (degree) } & $\eta(1 / \mathrm{s})$ & $E(\mathrm{~kJ} / \mathrm{mole})$ & $K_{g}(\mathrm{~W} / \mathrm{m}-\mathrm{K})$ & $K_{s}(\mathrm{~W} / \mathrm{m}-\mathrm{K})$ \\
\hline \multicolumn{2}{|c|}{3.82} & $\begin{array}{r}100 \text { (absorption) } \\
25 \text { (desorption) }\end{array}$ & 26.5 & $0.18\left(\mathrm{H}_{2}\right)$ & 30.75 \\
\hline
\end{tabular}

pressure and the desorption pressure of the PCI curves (pressure-composition isotherms), separately.

To define the pertinent problem completely, one needs to specify the boundary and initial conditions. For cooling/heating water circulating around the outer wall of the $\mathrm{MH}$ bed, while the end walls are insulated, the boundary conditions are

$$
\begin{gathered}
-K_{e} \frac{\partial T}{\partial r}=U\left[T(r, z, t)-T_{f}\right] \text { for } r=r_{0}, \\
0 \leq z \leq L, t>0 \\
\frac{\partial T}{\partial r}=0 \text { for } r=r_{i}, t>0 \\
\frac{\partial T}{\partial z}=0 \quad \text { for } z=0, \text { and } L, t>0
\end{gathered}
$$

where $r_{i}$ and $r_{o}$ denote the inner and outer radii of the MH bed, $T_{f}$ coolant temperature, $L$ the inner length of the reactor (i.e., the length of the $\mathrm{MH}$ bed), and $U$ the overall heat transfer co efficient. As for the initial condition, uniform temperature and concentration are specified, which are

$$
T(r, z, t)=T_{I} \text { for } r_{i} \leq r \leq r_{o}, 0 \leq z \leq L, t=0
$$

and

$$
x(r, z, t)=x_{I} \text { for } r_{i} \leq r \leq r_{o}, 0 \leq z \leq L, t=0
$$

In Eq. (10), $T_{I}$ denotes the initial temperature. In all the experiments and numerical simulations, $T_{I}$ is set to be equal to the coolant temperature $T_{f}$ and the initial concentration $x_{I}$ is set to be either zero for absorption and 1.02 for desorption.

The overall heat transfer coefficient $U$ can be expressed as

$$
U=\frac{1}{\frac{r_{o}}{r_{w} h}+\frac{r_{o} \ln \left(r_{w} / r_{o}\right)}{K_{w}}}
$$

where $r_{w}$ is the diameter of inner wall of the coolant channel, $K_{w}$ thermal conductivity of the wall, and $h$ the convective heat transfer coefficient in the channel, which is determined by the following empirical equation:

$$
N u=\frac{h D_{H}}{K_{f}}=0.023 \operatorname{Re}^{0.8} \operatorname{Pr}^{m}
$$

The above equation is for turbulent flow which is valid in the present problem. The three common dimensionless parameters $N u$, Re, and $P r$ are the Nusselt number, Reynolds number and Prandtl number, respectively. In addition, $D_{H}$ is the hydraulic diameter, $K_{f}$ the thermal conductivity of the coolant, and $m$ the exponent which is 0.4 for fluid heating and 0.3 for fluid cooling.

The above system of equations along with the boundary and initial conditions are solved by ADI (alternating direction implicit) scheme numerically. This method has the advantage of simplicity and good numerical stability. To save the computational time yet without sacrificing the accuracy, the number of the nodes was chosen to be $101 \times 101$, and the time step was set as one second. The properties of $\mathrm{LaNi}_{5}$ used in calculation are shown in Table 1, which is mainly based on [3, $8,24]$.

\section{RESULTS AND DISCUSSION}

\section{Results of Effective Thermal Conductivity}

Fig. 3 presents the experimental and calculated results of effective thermal conductivity of $\mathrm{LaNi}_{5}$ bed subject to various pressure conditions. In Fig. 3, the solid line denotes the calculated value based on the theory for $x=0$ (no hydrogen) and $\gamma=0.1$, while the symbols denote the experimental results. It should be mentioned that in Fig. 3, nitrogen rather than hydrogen was used in the experiment. It can be seen clearly that the theoretical result fits the experimental data quite well. In addition, the effective thermal conductivity does not vary sig- 


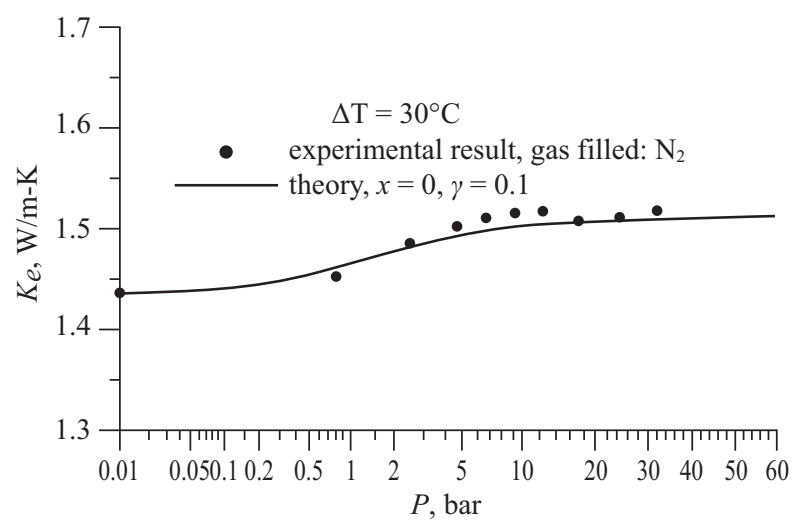

Fig. 3. Effective thermal conductivity of $\mathrm{LaNi}_{5}$ bed subject to various pressure conditions and plate heater temperature $60^{\circ} \mathrm{C}$, cooling water temperature $30^{\circ} \mathrm{C}$, and $\mathrm{MH}$ bed temperature $40^{\circ} \mathrm{C}$.

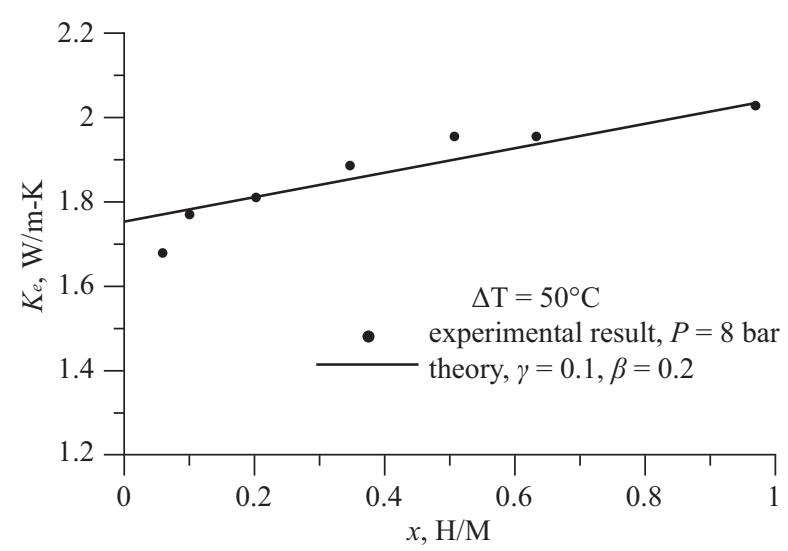

Fig. 4. The effect of hydrogen concentration on the effective thermal conductivity of $\mathrm{LaNi}_{5}$ bed for a fixed pressure $P=8$ bar and plate heater temperature $65^{\circ} \mathrm{C}$, cooling water temperature $15^{\circ} \mathrm{C}$, and MH bed temperature $30^{\circ} \mathrm{C}$.

nificantly with the gas pressure. Next, the effect of hydrogen concentration is shown in Fig. 4 for a fixed pressure $P=8$ bar. Both the theoretical and experimental results indicate that the effective thermal conductivity increases roughly linearly as the hydrogen concentration increases. Fig. 5 depicts the combined effect of pressure and hydrogen concentration for absorption/desorption processes. Due to hysteresis effect, the $K_{e}$ value for dsorption is higher than that for absorption. It can be found that the theoretical result agrees with the experimental result satisfactorily, although some discrepancy exists for hydrogen desorption process. It is quite crucial to check whether Sun and Deng's model can be applied to other metal hydrides. Fig. 6 presents the comparison between calculated results from Sun and Deng's $K_{e}$ model and experimental results from Suda et al. [15] for $\mathrm{TiMn}_{1.5}$. The agreement is even better. It can be concluded that Sun and Deng's theoretical model is suitable for predicting the effective thermal conductivity of common MH's and hence this model is cast in the full numerical model for simulating the hydrogen absorption/desorption process.

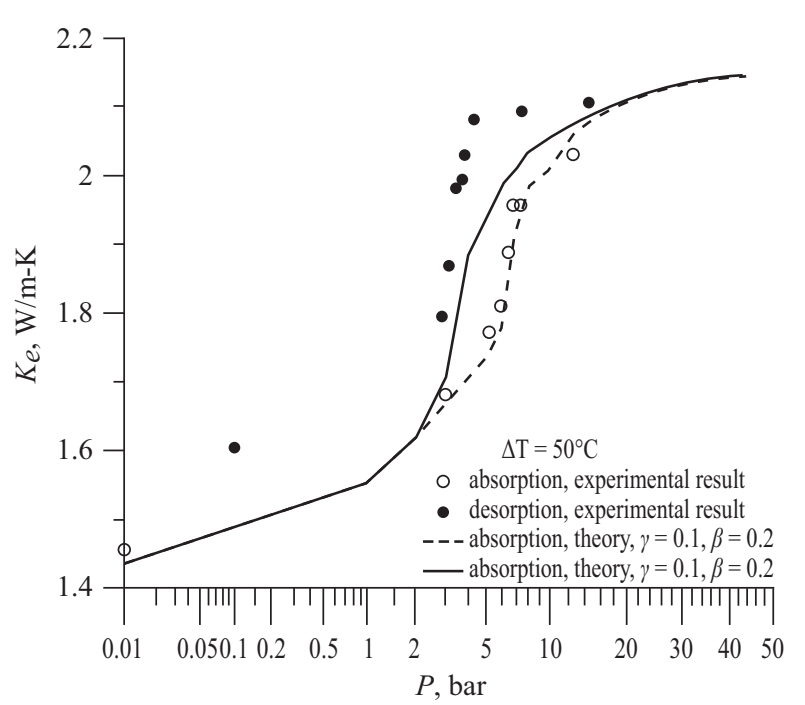

Fig. 5. The combined effect of pressure and hydrogen concentration for absorption/desorption processes in $\mathrm{LaNi}_{5}$ bed: plate heater temperature $65^{\circ} \mathrm{C}$, cooling water temperature $15^{\circ} \mathrm{C}$, and $\mathrm{MH}$ bed temperature $30^{\circ} \mathrm{C}$.

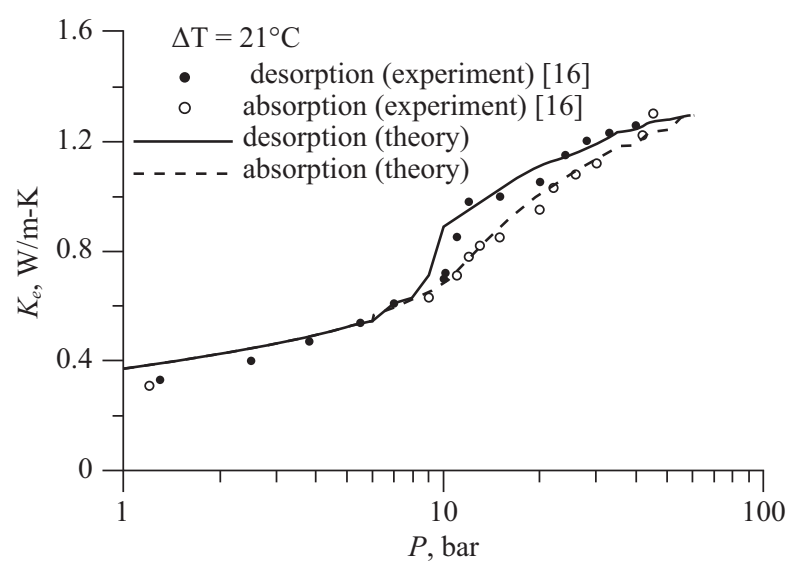

Fig. 6. Effective thermal conductivity of $\mathrm{TiMn}_{1.5}$ bed subject to various pressure conditions and plate heater temperature $45^{\circ} \mathrm{C}$, cooling water temperature $24^{\circ} \mathrm{C}$, and $\mathrm{MH}$ bed temperature $34.5^{\circ} \mathrm{C}$.

\section{Results for Hydrogen Absorption/Desorption in the Reactor}

Hydrogen absorption/desorption in the hydrogen storage reactor filled with $\mathrm{LaNi}_{5}$ is investigated both experimentally and numerically. Fig. 7(a) presents the accumulated hydrogen absorbed and Fig. 7(b) center temperature by assuming constant effective thermal conductivity $K_{e}=1 \mathrm{~W} / \mathrm{m}-\mathrm{K}$ for charging pressure of 16 bar under various coolant temperatures. Both experimental and numerical results are included in the figures. Fig. 7(a) indicates that lower temperatures yield more hydrogen absorbed. Because hydrogen absorption is exothermic reaction, the heat released during reaction slows down subsequent reaction for higher coolant temperatures. Fig. 7(b) displays the evolution of center temperature of $\mathrm{MH}$ bed versus time. Center temperature increases rapidly as soon as the 


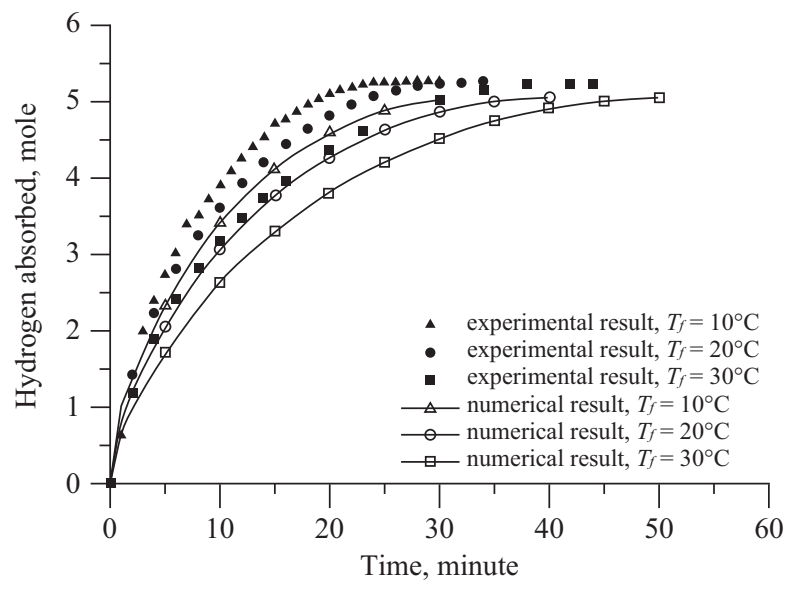

(a)

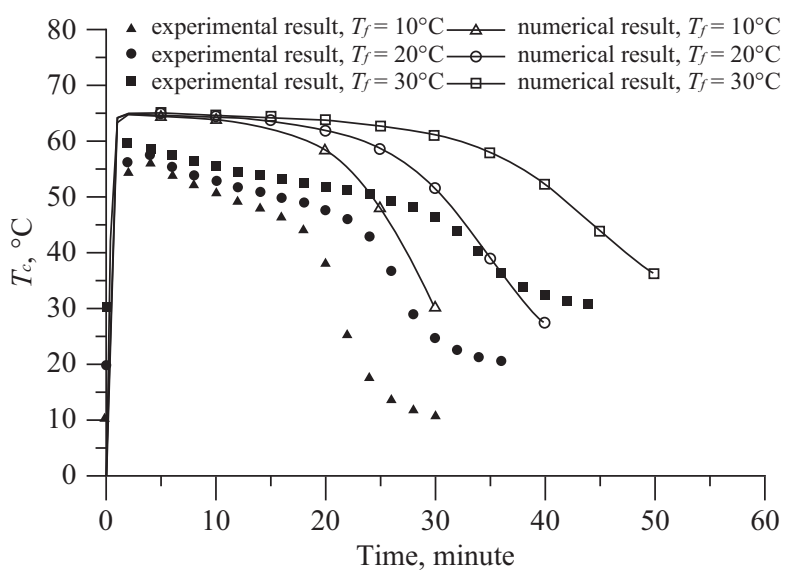

(b)

Fig. 7. Hydrogen absorption in the hydrogen storage reactor filled with $\mathrm{LaNi}_{5}$ by assuming constant effective thermal conductivity $K_{e}=1$ $\mathrm{W} / \mathrm{m}-\mathrm{K}$ for charging pressure of 16 bar under various coolant temperatures: (a) accumulated hydrogen absorbed and (b) center temperature.

reaction begins due to the sudden release of heat of formation. The temperature rise in the center temperature is larger for lower coolant temperatures due to faster reaction rates. Fig. 8 is similar to Fig. 7 except that Fig. 8 is obtained by employing the varied effective thermal conductivity model. It is obvious to see that the agreement between the numerical and experimental results improves significantly. It should be noted that the effect of charging pressure has been investigated elsewhere as in [24]. In general the higher the charging pressure, the faster the reaction rate.

The results for hydrogen desorption, are presented in Fig. 9 for constant $K_{e}$ of $1 \mathrm{~W} / \mathrm{m}-\mathrm{K}$ and Fig. 10 for varied $K_{e}$ for discharging pressure of 1 bar. Figs. 9(a) and 10(a) indicate that the desorption rate increases as the coolant temperature increases since hydrogen desorption of the $\mathrm{MH}$ is an endothermic reaction. Moreover, the center temperature drops down right after the desorption reaction occurs as shown in Figs. 9(b) and 10(b). Despite the discrepancy in the center temperature in Figs. 9(b) and 10(b) between the numerical and experimental

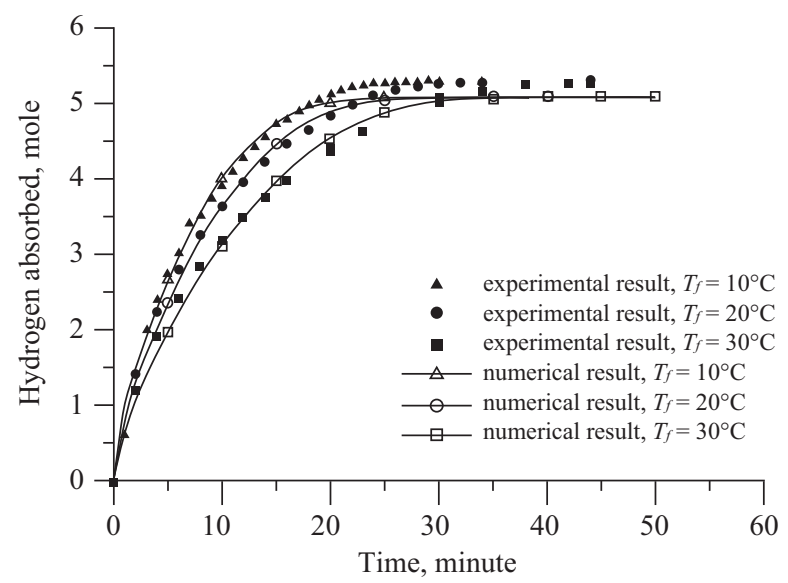

(a)

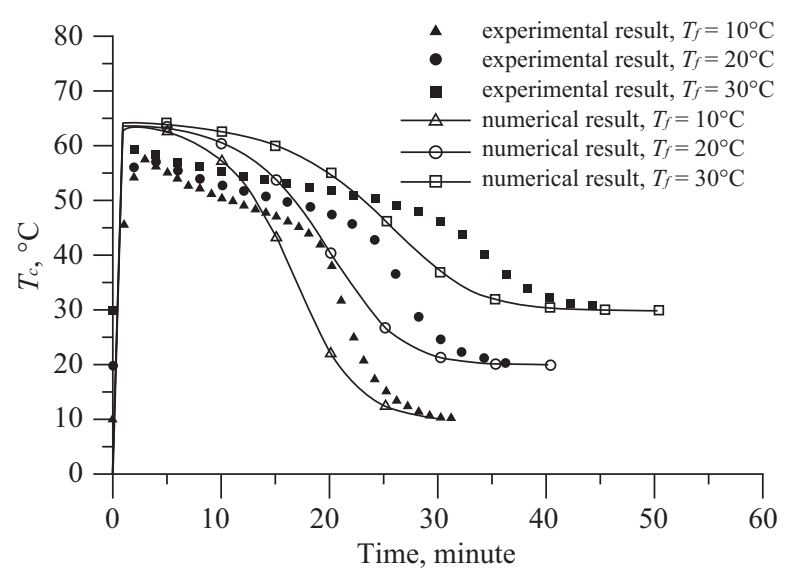

(b)

Fig. 8. Hydrogen absorption in the hydrogen storage reactor filled with $\mathrm{LaNi}_{5}$ by assuming varied effective thermal conductivity $K_{e}$ for charging pressure of 16 bar under various coolant temperatures: (a) accumulated hydrogen absorbed and (b) center temperature.

results, it can be found that the numerical results of hydrogen desorbed for the varied $K_{e}$ model still agree with the experimental results better than the numerical results for fixed $K_{e}$, by comparing Fig. 9(a) with Fig. 10(a). The above results clearly indicate the need of employing the varied $K_{e}$ model in the full numerical simulation of the $\mathrm{MH}$ absorption/desorption process.

\section{CONCLUSIONS}

This paper investigates hydrogen absorption/desorption in a hydrogen storage reactor experimentally and numerically. The results obtained from this study can be concluded in the following:

1. Satisfactory agreement was found between the results from the varied $K_{e}$ model and the measurement of the effective thermal conductivity.

2. The varied $K_{e}$ model is applicable to various metal hydrides. 


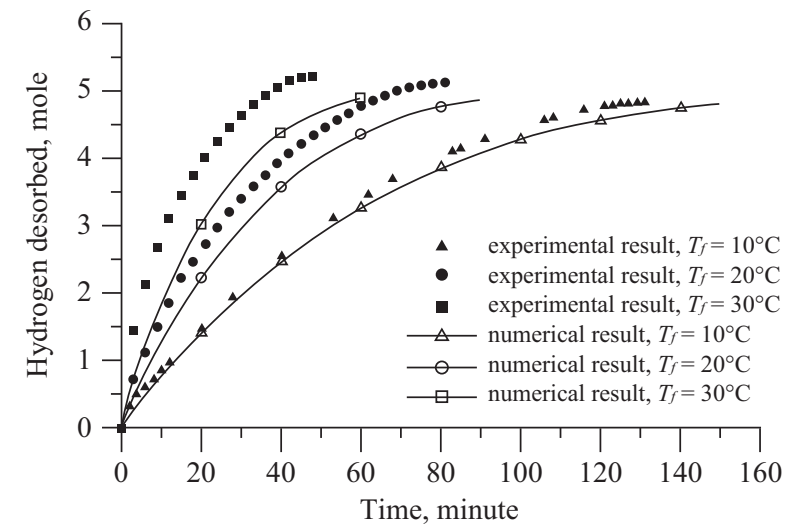

(a)

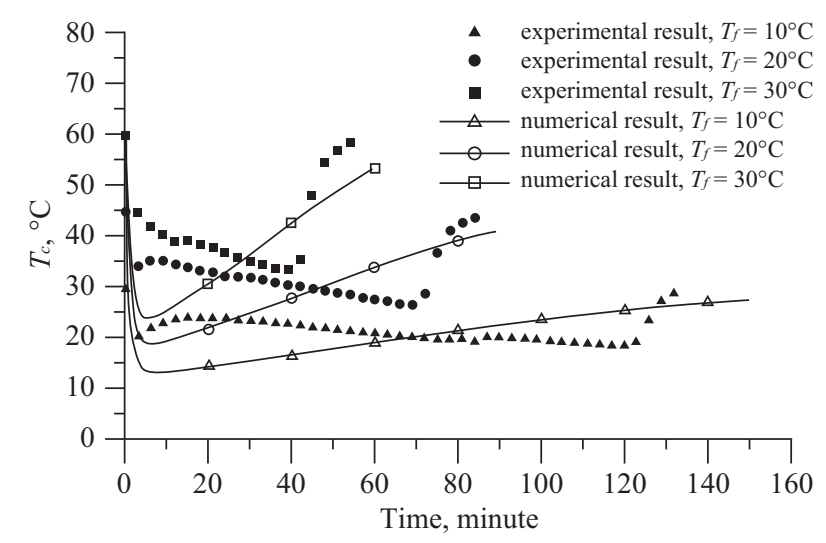

(b)

Fig. 9. Hydrogen desorption in the hydrogen storage reactor filled with $\mathrm{LaNi}_{5}$ by assuming constant effective thermal conductivity $K_{e}=1$ W/m-K for discharging pressure of 1 bar under various coolant temperatures: (a) accumulated hydrogen desorbed and (b) center temperature.

3. Absorption/desorption experiment was conducted for a $\mathrm{MH}$ bed. The fixed and the varied $K_{e}$ models were incorporated in the simulation of the absorption/desorption process in a hydrogen storage reactor, respectively. The comparison between the experimental results and the simulation clearly indicates better accuracy can be achieved by using the varied $K_{e}$ model.

\section{ACKNOWLEDGMENTS}

This work was carried out with financial support from the Taiwan Power Company of the ROC, Taiwan, under contract TPC-546-2415-9402C (from July 2004 to December 2005).

\section{NOMENCLATURE}

$A, B \quad$ constants of van't Hoff equation

$c \quad$ specific heat, $\mathrm{J} / \mathrm{kg}-\mathrm{K}$

$D_{H} \quad$ hydraulic diameter of the channel, $\mathrm{m}$

$E \quad$ activation energy of the $\mathrm{MH}, \mathrm{J} /$ mole

$f_{\text {hys }} \quad$ constant accounting for hysteresis

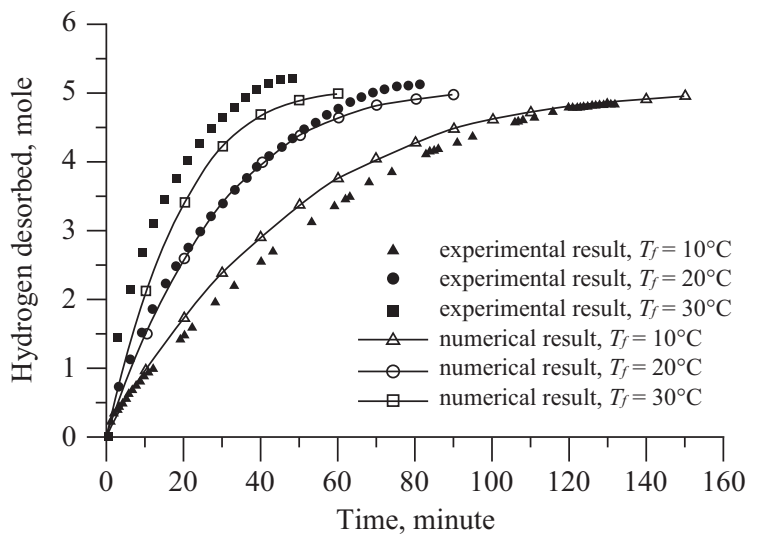

(a)

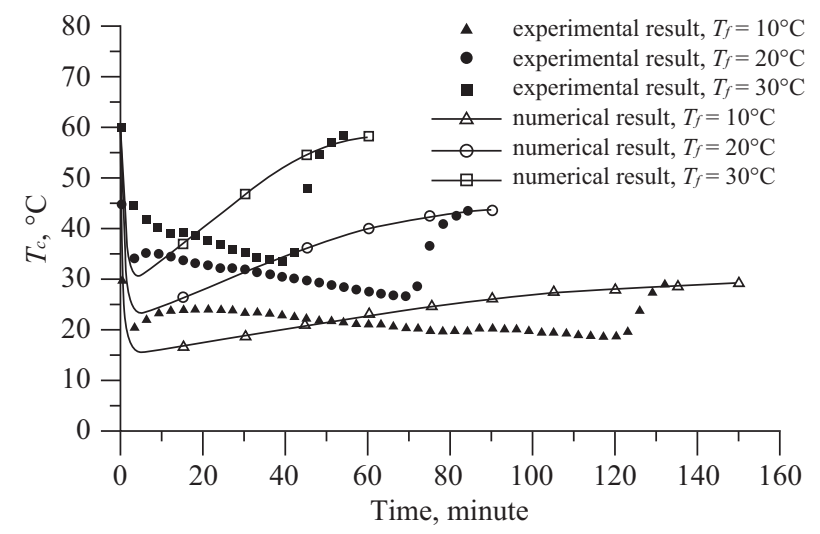

(b)

Fig. 10. Hydrogen desorption in the hydrogen storage reactor filled with $\mathrm{LaNi}_{5}$ by assuming varied effective thermal conductivity for dischargeing pressure of 1 bar under various coolant temperatures: (a) accumulated hydrogen desorbed and (b) center temperature.

$f_{p s}$

$\Delta H_{f} \quad$ heat of reaction of the $\mathrm{MH}, \mathrm{J} / \mathrm{mole}_{2}$

$h \quad$ convective heat transfer coefficient, $\mathrm{W} / \mathrm{m}^{2}-\mathrm{K}$

$h_{r s} \quad$ radiative heat transfer coefficient of the solid phase, $\mathrm{W} / \mathrm{m}^{2}-\mathrm{K}$

$h_{r v} \quad$ radiative heat transfer coefficient of the vapor phase, $\mathrm{W} / \mathrm{m}^{2}-\mathrm{K}$

$k$ thermal conductivity, $\mathrm{W} / \mathrm{m}-\mathrm{K}$

$K_{e} \quad$ effective thermal conductivity of the $\mathrm{MH}$ bed, $\mathrm{W} / \mathrm{m}-\mathrm{K}$

$K_{g} \quad$ thermal conductivity of the gas phase at atmospheric pressure, $\mathrm{W} / \mathrm{m}-\mathrm{K}$

$K_{g}{ }^{*} \quad$ thermal conductivity of the gas phase, $\mathrm{W} / \mathrm{m}-\mathrm{K}$

$K_{s} \quad$ thermal conductivity of the solid phase for $x=0$, $\mathrm{W} / \mathrm{m}-\mathrm{K}$

$K_{s}^{*} \quad$ thermal conductivity of the solid phase, $\mathrm{W} / \mathrm{m}-\mathrm{K}$

$L \quad$ length of the metal MH bed, $\mathrm{m}$

$M \quad$ molecular weight of the $\mathrm{MH}, \mathrm{kg} / \mathrm{kmole}$

$m \quad$ exponent in Eq. (12)

$N \quad$ number of atoms in each $\mathrm{MH}$ molecule 


$\begin{array}{ll}N u & \text { Nusselt number } \\ n & \text { number of moles of hydrogen } \\ P & \text { pressure, bar } \\ P r & \text { Prandtl number } \\ R e & \text { Reynolds number } \\ R u & \text { universal gas constant, } 8.314 \mathrm{~kJ} / \mathrm{kmole}-\mathrm{K} \\ r & \text { radial coordinate, } \mathrm{m} \\ r_{p} & \text { radius of the } \mathrm{MH} \text { particle, } \mathrm{m} \\ R & \text { radius of the } \mathrm{MH} \text { bed, } \mathrm{m} \\ T & \text { temperature, } \mathrm{K} \\ t & \text { time, } \mathrm{s} \\ U & \text { overall heat transfer coefficient, } \mathrm{W} / \mathrm{m}^{2}-\mathrm{K} \\ x & \text { hydrogen concentration, number of hydrogen atoms/ } \\ & \text { total number of atoms per alloy molecule, }[\mathrm{H}] /[\mathrm{M}] \\ z & \text { axial coordinate, } \mathrm{m}\end{array}$

Greek Symbols

$\begin{array}{ll}\beta, \gamma & \text { accommodation coefficients } \\ \varepsilon & \text { porosity } \\ \gamma_{h} & \text { reaction rate of the } \mathrm{MH}, \mathrm{mol} \mathrm{H}_{2} /(\mathrm{kg} \text { hydride })-\mathrm{s} \\ \eta & \text { reaction rate constant, } 1 / \mathrm{s} \\ \rho & \text { density, } \mathrm{kg} / \mathrm{m}^{3} \\ \omega & \text { emissivity } \\ \theta & \text { contact angle between solid particles }\end{array}$

\section{Subscripts}

$\begin{array}{ll}a v g & \text { absorption } \\ b & \text { average } \\ c & \text { metal hydride bed } \\ d & \text { centerline of the } \mathrm{MH} \text { bed } \\ e q & \text { desorption } \\ F & \text { equilibrium } \\ f & \text { final } \\ I & \text { fluid } \\ i & \text { initial } \\ M H & \text { inner } \\ m & \text { metal hydride } \\ o & \text { medium } \\ w & \text { outer }\end{array}$

\section{REFERENCES}

1. Botzung, M., Chaudourne, S., Gillia, O., Perret, C., Latroche, M., Percheron-Guegan, A., and Marty, P., "Simulation and experimental validation of a hydrogen storage tank with metal hydrides," International Journal of Hydrogen Energy, Vol. 33, pp. 98-104 (2008).

2. Choi, H. and Mills, A. F., "Heat and mass transfer in metal hydride beds for heat pump applications," International Journal of Heat and Mass Transfer, Vol. 33, pp. 1281-1288 (1990).

3. Gambini, M., "Performance of metal hydride heat pumps operating under dynamic conditions," International Journal of Hydrogen Energy, Vol. 14, pp. 821-830 (1989).

4. Gopal, M. R. and Murthy, S. S., "Prediction of heat and mass transfer in annular cylindrical metal hydride beds," International Journal of Hydrogen Energy, Vol. 17, pp. 795-805 (1992).

5. Gopal, M. R. and Murthy, S. S., "Performance of a metal hydride cooling system," International Journal of Refrigeration, Vol. 18, pp. 413-420
(1995).

6. Gopal, M. R. and Murthy, S. S., "Prediction of metal-hydride refrigerator performance based on reactor heat and mass transfer," International Journal of Hydrogen Energy, Vol. 20, pp. 607-614 (1995).

7. Gopal, M. R. and Murthy, S. S., "Studies on heat and mass transfer in metal hydride beds," International Journal of Hydrogen Energy, Vol. 20, pp. 911-917 (1995)

8. Huston, E. L. and Sandrock, G. D., "Engineering properties of metal hydrides," Journal of the Less Common Metals, Vol. 74, No. 2, pp. 435-443 (1980)

9. Ishido, Y., Kawamura, M., and Ono, S., "Thermal conductivity of magnesium-nickel hydride powder beds in a hydrogen atmosphere," International Journal of Hydrogen Energy, Vol. 7, No. 2, pp. 173-182 (1982).

10. Jemni, A. and Nasrallah, S. B., "Study of two-dimensional heat and mass transfer during absorption in a metal-hydrogen reactor," International Journal of Hydrogen Energy, Vol. 20, pp. 43-52 (1995).

11. Jemni, A. and Nasrallah, S. B., "Study of two-dimensional heat and mass transfer during desorption in a metal-hydride reactor," International Journal of Hydrogen Energy, Vol. 20, pp. 881-891 (1995).

12. Mayer, U., Groll, M., and Supper, W., "Heat and mass transfer in metal hydride reaction beds: experimental and theoretical results," Journal of the Less-Common Metals, Vol. 131, pp. 235-244 (1987).

13. Mohan, G., Maiya, M. P., and Murthy, S. S., "Performance simulation of metal hydride hydrogen storage device with embedded filters and exchangers tubes," International Journal of Hydrogen Energy, Vol. 32, pp. 4978-4987 (2007).

14. Muthukumar, P., Madhavakrishna, U., and Dewan, A., "Parametric studies on a metal hydride based hydrogen storage device," International Journal of Hydrogen Energy, Vol. 32, pp. 4988-4997 (2007).

15. Suda, S., Kobayashi, N., and Yoshida, K., "Thermal conductivity in metal hydride beds," International Journal Hydrogen Energy, Vol. 6, pp. 521528 (1981).

16. Suda, S., Kobayashi, N., Yoshida, K., Ishido, Y., and Ono, S., "Experimental measurements of thermal conductivity," Journal of the LessCommon Metals, Vol. 74, pp. 127-136 (1980).

17. Suda, S., Komazaki, Y., and Kobayashi, N., "Effective thermal conductivity of metal hydride beds," Journal of the Less Common Metals, Vol. 89, No. 2, pp. 317-324 (1983).

18. Suissa, E., Jacob, I., and Hadari, Z., "Experimental measurements and general conclusions on the effective thermal conductivity of powdered metal hydrides," Journal of the Less-Common Metals, Vol. 104, pp. $287-$ 295 (1984).

19. Sun, D. W. and Deng, S. J., "A theoretical model predicting the effective thermal conductivity in powdered metal hydride beds," International Journal of Hydrogen Energy, Vol. 15, No. 5, pp 331-336 (1990).

20. Sun, D. W. and Deng, S. J., "Theoretical descriptions and experimental measurements on the effective thermal conductivity in metal hydride powder beds," Journal of the Less Common Metals, Vol. 160, No. 2, pp. 387-395 (1990).

21. Sun, D. W. and Deng, S. J., "Study of the heat and mass transfer characteristics of metal hydride beds," Journal of the Less-Common Metals, Vol. 141, pp. 37-43 (1988).

22. Sun, D. W. and Deng, S. J., "Study of the heat and mass transfer characteristics of metal hydride beds: a two-dimensional model," Journal of the Less-Common Metals, Vol. 155, pp. 271-279 (1989).

23. Sun, D. W. and Deng, S. J., "Numerical solution of the two-dimensional non-steady heat and mass transfer problem in metal hydride beds," International Journal of Hydrogen Energy, Vol. 15, pp. 807-816 (1990).

24. Wang, W. S., A Study on Heat and Mass Transfer in Metal-Hydrogen Reactors, Master Thesis, Department of Mechanical and Mechatronic Engineering, National Taiwan Ocean University, Keelung, Taiwan (2005).

25. Yang, F., Meng, X., Deng, J., Wang, Y., and Zhang, Z., "Identifying heat and mass transfer characteristics of metal hydride reactor during adsorption-parameter analysis and numerical study," International Journal of Hydrogen Energy, Vol. 33, pp. 1014-1022 (2008). 